\title{
形状記憶合金エンジンの出力密度に関する研究*
}

\author{
佐藤義久 ${ }^{* 1}$ ，吉嶺和哉 ${ }^{* 2}$, 内山元気 ${ }^{* 2}$, 渡邊敬之 ${ }^{* 2}$
}

\section{Study on the Output Power Density of the Shape Memory Alloy Engine}

\author{
Yoshihisa SATO*1 $^{*}$ Kazuya YOSHIMINE, Genki UCHIYAMA and Takayuki WATANABE
}

\author{
${ }^{* 1}$ Department of Electrical and Electronic Engineering \\ Daido University, 10-3 Takiharu-cho, Minami-ku, Nagoya, 457-8530 Japan
}

The purpose of this research is to clarify the requirements for the high output power density of SMA engine. In order to put the SMA engine in practical use, maximizing the output power density is most important from the viewpoint of economical efficiency. The output power of the SMA engine highly depends on the diameter of the SMA belt and the radius of the high temperature wheel. In this study we will change the diameter of the SMA belt and theoretically explain whether there is a relational expression between it and the radiuses of the high temperature wheel and the low temperature wheel of the SMA engine. If the radius of the low temperature wheel $(R)$ is determined, the equipment width $(W)$ of the SMA engine is also determined $(W=2 R)$. Next, the height of the SMA engine is determined experimentally by the cooling conditions of the SMA belt. Finally, the depth of the SMA engine is determined by the diameter of the SMA belt $(D=d)$. Since the output power of the SMA engine can be calculated by the theoretical formula, we can divide it by the volume of the SMA engine and thus, calculate the output power density of the SMA engine. As the result, changing the diameter of the SMA belt, we can calculate the most appropriate value, at which the output power density of the SMA engine is maximal.

Key Word : Shape Memory Alloy, SMA Engine, Energy Conversion, Output Power Density

\section{1. 緒言}

地球温暖化防止の観点から，火力発電所蒸気タービン排熱，工場ボイラ排熱あるいはガス給湯器の排熱等の未利用低 温熱エネルギーを有効活用することが必要不可欠である. 単純プーリ型形状記憶合金(SMA : Shape Memory Alloy)エンジ ンに関しては既に W.S.Ginell, 戸伏, 岩永等によって基礎的な研究が行われている(1)(2)(3). しかし，SMAエンジンの回転 メカニズム, 回転角速度, 出力が理論的に未解明であった. 著者等はこれらの研究をさらに発展させ, SMA エンジン の回転角速度 $\omega_{\max }\left[\mathrm{sec}^{-1}\right]$, 出力 $P_{\max }[\mathrm{W}]$ を $\mathrm{SMA}$ ベルトの断面形状・寸法・長さ, SMA エンジンの高温輪の半径 $r$ および 低温輪の半径 $R, \mathrm{SMA}$ ベルトの高温域のヤング率 $E_{1}$ および低温域のヤング率 $E_{2}$ のみから予測可能な理論式を導出し, その妥当性を大型 SMA 実験装置を用いて実験的に検証した ${ }^{(4)}$.さらに，理論式を用いた解析により，高出力化の方向 性を明らかにした (5). 従来の研究は高出力化を中心に SMA エンジンの出力特性を研究してきたが，SMA エンジンを実 用化する際には, 限られたスペースで如何に高い出力が得られるようにするか, つまり出力密度を最大化する必要があ る. 本研究の目的は, SMA エンジンの出力密度が最大となる設計手法を明らかにすることである.

\section{2. 主な記号}

$d \quad: \mathrm{SMA}$ ベルトの直径 $[\mathrm{mm}]$

$r \quad:$ 高温輪の半径 $[\mathrm{cm}]$

* 原稿受付 2011 年 3 月 30 日

*1 正員, 大同大学（广457-8530 愛知県名古屋市南区滝春町 10-3）

*2 大同大学大学院工学研究科電気・電子工学専攻

E-mail: satoy@daido-it.ac.jp 


\begin{tabular}{|c|c|}
\hline$R$ & : 低温輪の半径 $[\mathrm{cm}]$ \\
\hline$L$ & : SMA ベルトの長さ[m] \\
\hline$J_{1}$ & : 高温輪の慣性モーメント $\left[\mathrm{kg} ・ \mathrm{~m}^{2}\right]$ \\
\hline$J_{2}$ & : 低温輪の慣性モーメント $\left[\mathrm{kg} ・ \mathrm{~m}^{2}\right]$ \\
\hline$E_{1}$ & : SMA ベルトの高温域のヤング率[GPa] \\
\hline$E_{2}$ & : SMA ベルトの低温域のヤング率[GPa] \\
\hline$M$ & : SMA ベルトの曲げモーメント $[\mathrm{N} ・ \mathrm{~m}]$ \\
\hline$M_{\mathrm{h}}$ & : 高温輪の回転モーメント $[\mathrm{N} ・ \mathrm{~m}]$ \\
\hline$\omega_{1}$ & : 高温輪の回転角速度 $\left[\mathrm{sec}^{-1}\right]$ \\
\hline$\omega$ & : 低温輪の回転角速度 $\left[\mathrm{sec}^{-1}\right]$ \\
\hline$T$ & : 出力輪(低温輪)のトルク $[\mathrm{N} \cdot \mathrm{m}]$ \\
\hline$P$ & :SMA エンジンの出力[W] \\
\hline$R \omega$ & : SMA ベルトの速度[m/s] \\
\hline$n$ & : SMA ベルトの周回数 \\
\hline$t$ & : SMA ベルトの温度 $\left.{ }^{\circ} \mathrm{C}\right]$ \\
\hline$\ell$ & :弦長(高温輪・低温輪の中心間距離) $[\mathrm{m}]$ \\
\hline$W$ & :SMA エンジンの幅[m] \\
\hline$H$ & :SMA エンジンの高さ[m] \\
\hline$D$ & :SMA エンジンの奥行[m] \\
\hline$V$ & :SMA エンジンの体積 $\left[\mathrm{m}^{3}\right]$ \\
\hline
\end{tabular}

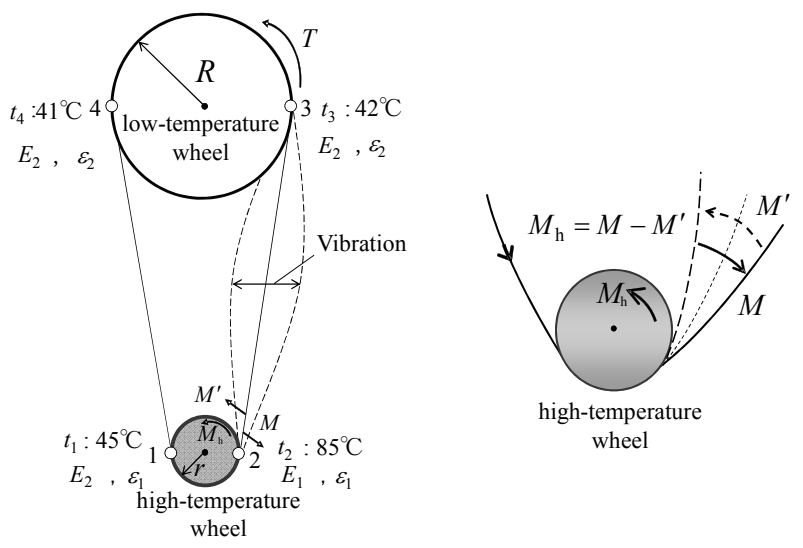

Fig. 1 The symbols of experiment equipment

\section{3. 研究の目的}

SMA ベルトは図 1 に示すように，点 1 で高温輪に接して曲げられ(ひずみ $\varepsilon_{1}$, ヤング率 $\left.E_{2}\right)$ ，お湯に浸かり加熱されな がら回転し, 点 2 で変態温度に達し真っ直ぐになろうとし(ひずみ $\varepsilon_{1}$, ヤング率 $\left.E_{1}\right)$, 曲げモーメント $M$ を発生する. そ の後, SMA ベルトは引き戻され, 曲げモーメント $M^{\prime}$ を発生する. この曲げモーメントの差 $M-M^{\prime}$ が SMA エンジン の回転モーメント $M_{\mathrm{h}}$ となり，SMA ベルトはこの動作を繰り返し，振動しながら回転し続ける. SMA エンジンの回転 角速度 $\omega_{\max }\left[\mathrm{sec}^{-1}\right]$ および出力 $P_{\max }[\mathrm{W}]$ を予測する理論式は SMA エンジンの外形的な諸量 $\left(d, r, R, L, J_{1}, J_{2}, E_{1}, E_{2}\right)$ のみを用いて式(1)のように導出されるが，SMA エンジンを実用化するためには，経済性の観点より，SMA エンジンの 出力密度を最大化することが必要不可欠である. そこで, 本研究の目的は, SMA ベルトの直径 $d$ を変化させた場合に, 高温輪の半径 $r$, 低温輪の半径 $R, \mathrm{SMA}$ ベルトの長さ $L, \mathrm{SMA}$ エンジンの高さ $H$ および奥行寸法 $D$ がどのような条件 で決定されるかをそれぞれ明らかにし，SMA エンジンの出力密度を最大化する設計手法を明確にすることである. 


\section{SMA ベルトの直径 $d$ について}

$\mathrm{SMA}$ エンジンの回転角速度 $\omega_{\max }$, 出力 $P_{\text {max }}$ は SMA エンジンの外形的な諸量 $\left(d, r, R, L, J_{1}, J_{2}, E_{1}, E_{2}\right)$ のみから 式(1)を用いて求めることができる(4). 式(1)を用いた解析および実駼結果によれば，SMA エンジンの出力 $P_{\text {max }}$ は SMA ベルトの直径 $d$ に強く依存し, SMA ベルトの直径 $d$ を大きくすればするほど出力 $P_{\max }$ は大きくなる(5). しかし, SMA ベルトの直径 $d$ には製造限界が存在するので, 直径 $d$ は製造限界の $2.0 \mathrm{~mm}$ を最大值とし, 今後の検討および実験に用 いる SMA ベルトの直径は, $d=1.2 \mathrm{~mm}, 1.5 \mathrm{~mm}, 2.0 \mathrm{~mm} の 3$ 種類とする.

$P_{\text {max }}=\frac{\omega_{\max }}{2} \cdot \frac{\pi d^{4} R\left(E_{1}-E_{2}\right)}{128 r^{2}}[\mathrm{~W}] \quad$ 但し, $\omega_{\max }=\sqrt{\frac{n \pi d^{4} L r^{2}\left(\frac{E_{1}-E_{2}}{r^{2}}-\frac{2 E_{2}}{R^{2}}\right)}{64\left(J_{1} R^{2}+J_{2} r^{2}\right)}}\left[\sec ^{-1}\right], n=2,3$

\section{5. 高温輪の半径 $r$ の決定方法}

SMA エンジンの出力 $P_{\max }$ は SMA エンジンの高温輪の半径 $r$ に強く依存し, 高温輪の半径 $r$ を小さくするほど出力 $P_{\max }$ は大きくなる(5). しかし, 高温輪の半径 $r$ には SMA ベルトが高温輪にしっかり捲きつく為のひずみおよび弾性限界 より決まる下限值が存在する. すなわち, 従来の実験結果 ${ }^{(4)(5)}$ によればSMAベルトのひずみを $1.0 〜 1.5 \%$ 以下にする必 要があることが分かっている. $\varepsilon=d / 2 r \leqq 1.3 \%$ (必要条件)より, 高温輪の半径 $r$ は SMA ベルトの直径 $d$ を決めれば, 式 (2)で一義的に決定される.

$r_{\min } \geqq d /(2 \times 1.3 \%)=37.5 d[\mathrm{~mm}]$

したがって，3 種類の SMA ベルトに対して高温輪の半径(下限值)は表 1 の通りとなる.
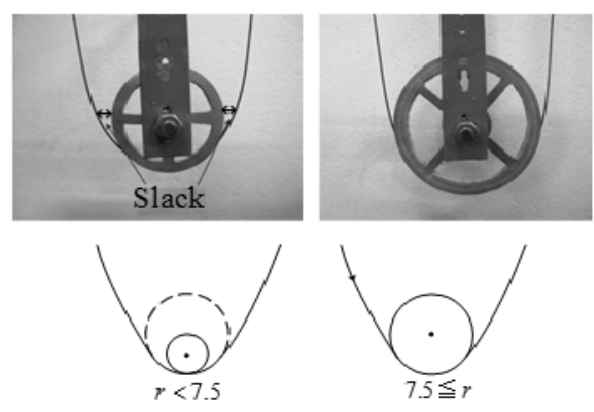

$$
\varepsilon>1.3 \% \quad \varepsilon=\frac{d}{2 r} \leq 1.3 \%
$$

Fig. 2 Relation between $r$ and curvature radius of SMA belt $(d=2.0 \mathrm{~mm})$

Table 1 Relation between $d$ and $r_{\min }$

\begin{tabular}{|c|c|c|c|}
\hline Diameter of SMA belt $d$ & $1.2 \mathrm{~mm}$ & $1.5 \mathrm{~mm}$ & $2.0 \mathrm{~mm}$ \\
\hline Radius of high temperature wheel $r_{\text {min }}$ & $4.5 \mathrm{~cm}$ & $5.6 \mathrm{~cm}$ & $7.5 \mathrm{~cm}$ \\
\hline
\end{tabular}

\section{6. 低温輪の半径 $R$ の決定方法}

\section{$6 \cdot 1$ 低温輪の半径 $R$ の決定方法}

次に, 低温輪の半径 $R$ の決定方法について検討寸る. 従来の研究成果 ${ }^{(4)(5)} よ り, P_{\max }$ が最大となる低温輪の半径 $R$ が 存在することが分かっている. 表 1 に示寸高温輪の半径 $r$ および実験的に求めた SMA ベルトの長さ $L$ を用い, 式(1)を 用いた解析を行い, SMA エンジンの出力 $P_{\max }$ が最大となる低温輪の半径 $R$ を求めた. 解析結果を表 2 に示す.

Table 2 Relation between $d$ and $R$

\begin{tabular}{|c|c|c|c|}
\hline Diameter of SMA belt $d$ & $1.2 \mathrm{~mm}$ & $1.5 \mathrm{~mm}$ & $2.0 \mathrm{~mm}$ \\
\hline Radius of low temperature wheel $R$ & $12.5 \mathrm{~cm}$ & $12.5 \mathrm{~cm}$ & $20 \mathrm{~cm}$ \\
\hline
\end{tabular}




\section{$6 \cdot 2$ 低温輪の半径 $R$ の決定方法に関する実験的検証}

式(1)を用いた解析で決定した低温輪の半径 $R$ が適切であるか否か実験的に検証する. SMAベルトの直径 $d$ を決定す れば, 高温輪の半径 $r$ が一義的に決定できるので, 式(1)より SMA エンジンの出力 $P_{\max }$ と SMA ベルトの速度 $R \omega_{\max }$ は 比例することがわかる $\left(P_{\text {max }} \propto R \omega_{\max }\right)$. したがって，実験が比較的容易で測定精度が高い SMA ベルトの速度 $R \omega_{\max }$ で検 証を行う. 実験方法は, SMA ベルトの直径および, 式(2)で決定した高温輪の半径の最適值 $(d=2.0 \mathrm{~mm}$ のとき $r=7.5 \mathrm{~cm}$, $d=1.5 \mathrm{~mm}$ のとき $r=5.6 \mathrm{~cm}, d=1.2 \mathrm{~mm}$ のとき $r=4.5 \mathrm{~cm})$ に対して, 解析で求めた低温輪の半径を目途に, 低温輪の半径を変 化させ, その時の低温輪の回転角速度 $\omega$ を測定し, SMA ベルトの速度 $R \omega か ゙$ 最大となる值を最適な低温輪の半径とする. 尚, 実験時のSMA ベルトの長さは表 3 に示寸值を用いた.

\section{$6 \cdot 3$ 実験結果}

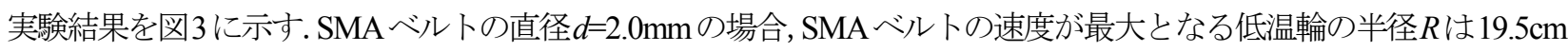
である，一方，解析から得られる低温輪の半径 $R$ は $20 \mathrm{~cm}$ であり，実験值と解析值はよく一致している．同様に実験を 行った結果, $\mathrm{SMA}$ ベルトの直径 $d=1.5 \mathrm{~mm}$ の場合, $\mathrm{SMA}$ ベルトの速度が最大となる低温輪の半径 $R$ は, 実験值及び解 析值共に $R=12.5 \mathrm{~cm}$ で一致した. SMA ベルトの直径 $d=1.2 \mathrm{~mm}$ の場合, 実験值は $R=10 \mathrm{~cm}$, 解析值は $R=12.5 \mathrm{~cm}$ であり, 比較的よく一致した.

いずれの SMA ベルトの直径においても傾向は類似しており，SMA ベルトの速度が最大となる低温輪の半径 $R$ の実 験值と, 解析值がよく一致する.つまり, 低温輪の半径 $R$ は式(1)を用いた解析により決定できることがわかった.

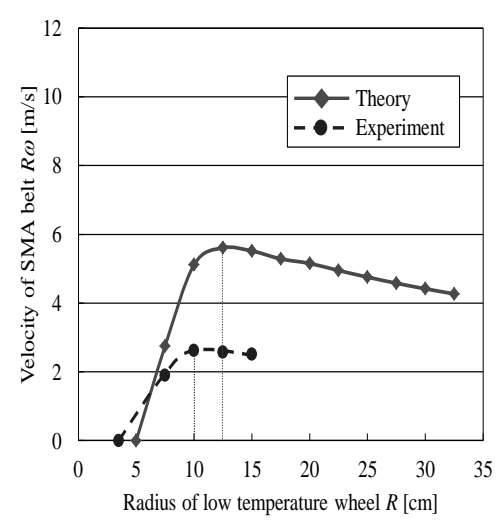

(a) $d=1.2 \mathrm{~mm}$

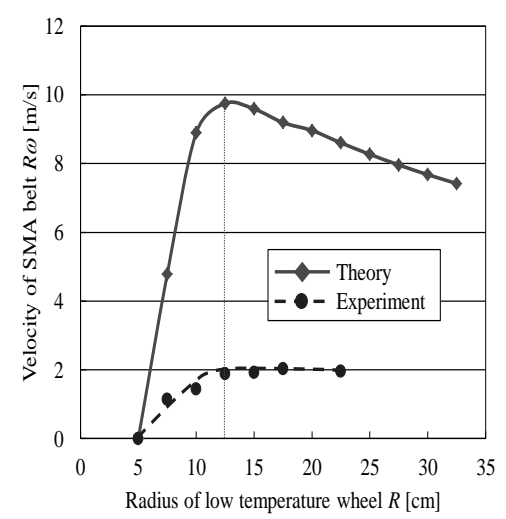

(b) $d=1.5 \mathrm{~mm}$

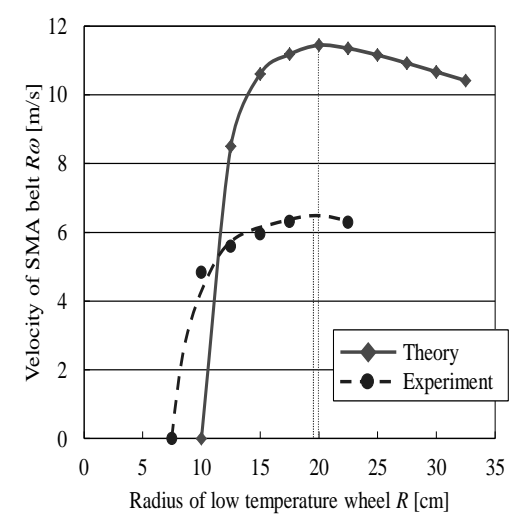

(c) $d=2.0 \mathrm{~mm}$

Fig. 3 Optimal radius of the low temperature wheel $R$

(when velocity of SMA belt reaches its maximum)

\section{SMA エンジンの出力密度 $P / V$}

\section{$7 \cdot 1$ 装置幅 $W$}

ここまでの実験結果より SMA ベルトの直径 $d$ を決めることで, 式(2)を用いた高温輪の決定方法より出力が最大とな る最適な高温輪の半径が決定でき, それらの值と式(1)を用いた解析結果より, 出力が最大となる低温輪の半径が決定で きることがわかった.

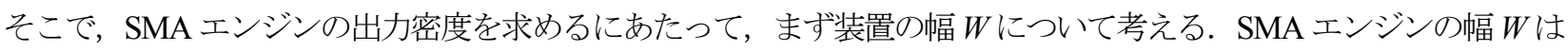
図 4 に示寸ように低温輪の直径，つまり $W=2 R$ となる．したがって，SMA ベルトの直径 $d=2.0 \mathrm{~mm}$ の場合，装置の幅 $W=2 \times 20 \mathrm{~cm}=40 \mathrm{~cm}$ となる. 同様に, SMA ベルトの直径 $d=1.5 \mathrm{~mm}$ の場合, 装置の幅 $W=25 \mathrm{~cm}, \mathrm{SMA}$ ベルトの直径 $d=1.2 \mathrm{~mm}$ の場合, 装置の幅 $W=25 \mathrm{~cm}$ となる. 


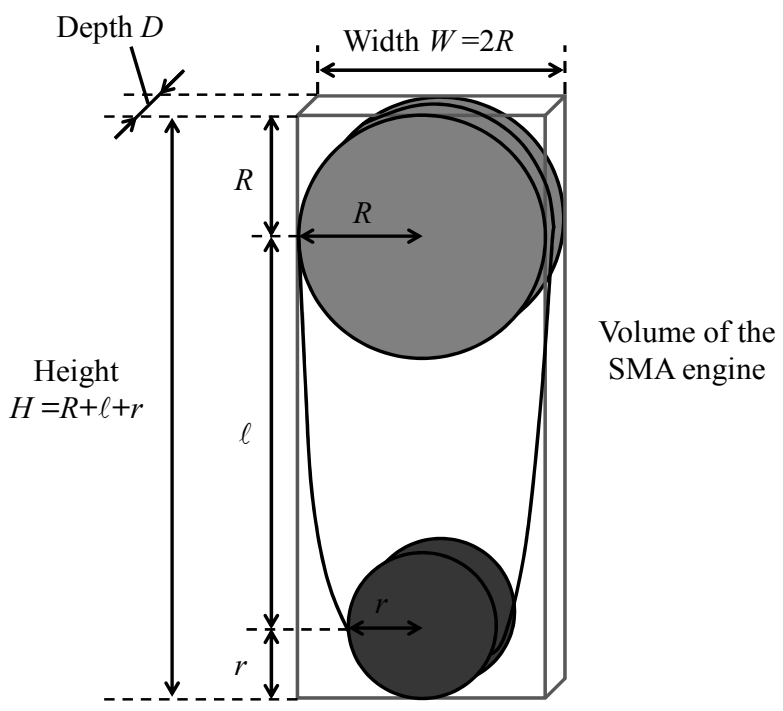

Fig. 4 Volume of the SMA engine

\section{$7 \cdot 2$ 装置高さ $\boldsymbol{H}$}

次に, 装置の高さについて考える. 装置の高さ $H$ は, 図 4 に示すように低温輪の半径 $R$, 高温輪の半径 $r$ および高温 輪・低温輪の中心間距離である弦長 $\ell$ 用いて, 装置の高さ $H=R+r+\ell$ で求めることができる．SMAベルトの長さ には SMA エンジンの放熱の観点より出力が最大となる最適值が存在する(図 5 参照). 図 5 より, SMA ベルトの直径 $d=2.0 \mathrm{~mm}$ の場合, SMA エンジンの出力が最大となる SMA ベルトの長さは $L=5.75 \mathrm{~m}$ となることがわかる．同様に自然 冷却条件より, SMA ベルトの直径 $d=1.5 \mathrm{~mm}$ の場合, 最適な SMA ベルトの長さ $L=5.2 \mathrm{~m}, \mathrm{SMA}$ ベルトの直径 $d=1.2 \mathrm{~mm}$ の場合，最適な SMA ベルトの長さ $L=4.2 \mathrm{~m}$ となる. SMA ベルトの長さ $L=\pi(R+r)+2 \ell の$ 関係より，SMA ベルトの直径 $d=2.0 \mathrm{~mm}$ の場合, 弦長 $\ell=2.44 \mathrm{~m}, \mathrm{SMA}$ ベルトの直径 $d=1.5 \mathrm{~mm}$ の場合, 弦長 $\ell=2.32 \mathrm{~m}$, SMA ベルトの直径 $d=1.2 \mathrm{~mm}$ の場

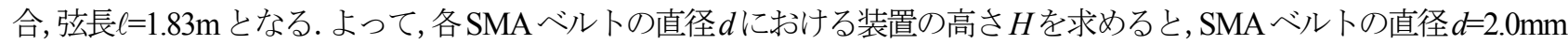
の場合, 装置の高さ $H=0.20+0.075+2.44=2.72 \mathrm{~m}$ となる. 同様に, SMA ベルトの直径 $d=1.5 \mathrm{~mm}$ の場合, 装置の高さ $H=2.50 \mathrm{~m}$, SMA ベルトの直径 $d=1.2 \mathrm{~mm}$ の場合, 装置の高さ $H=2.00 \mathrm{~m}$ となる.

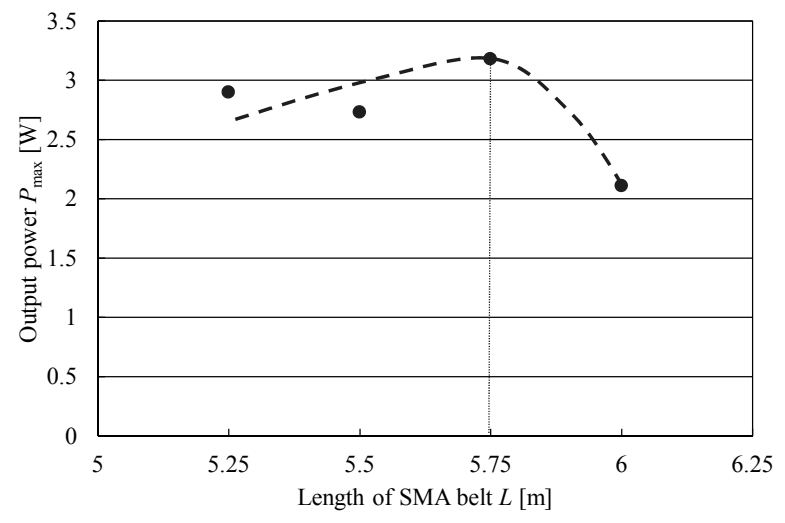

Fig. 5 Optimal Length of the SMA belt ( $d=2.0 \mathrm{~mm})$

\section{$7 \cdot 3$ 装置奥行 $D$}

(when output power of the SMA engine reaches its maximum)

装置奥行 $D$ につては, SMA エンジンの設計・製作条件より, 図6に示すように考えている. SMAベルトの直径 $d$ を決めると，スリーブの厚さ $D_{1}$ は $D_{1}=d / 2 \times 0.9$ となる．次に，間隔(クリアランス) $D_{2}$ は SMA ベルトの直径とスリー ブの厚さによって変化するので, $D_{2}=\left(d+2 D_{1}\right) / 2$ とした. さらに, 車輪の縁の厚さ $D_{3}$ は車輪の強度によって決まり, $0.6 \mathrm{~mm}$ とした. したがって, 装置奥行 $D$ は $D=d+2 \times\left(D_{1}+D_{2}+D_{3}\right)$ で求めることができる. つまり, SMA ベルトの直径 $d=2.0 \mathrm{~mm}$ 
の場合, 装置奥行 $D$ は $D=2.0+2 \times(0.9+1.9+0.6)=8.8 \mathrm{~mm}$ となる. 同様に, SMA ベルトの直径 $d=1.5 \mathrm{~mm}$ の場合, 装置奥行 $D=6.9 \mathrm{~mm}, \mathrm{SMA}$ ベルトの直径 $d=1.2 \mathrm{~mm}$ の場合, 装置奥行 $D=5.6 \mathrm{~mm}$ となる. しかし, スリーブの厚さ $D_{1}$, クリアラン ス $D_{2}$, 車輪の縁の厚さ $D_{3}$ には設計上の要素が含まれる為, 出力密度を算出寸る奥行 $D$ は, SMA ベルトの直径 $d$ を用 いることとする $(D=d)$.

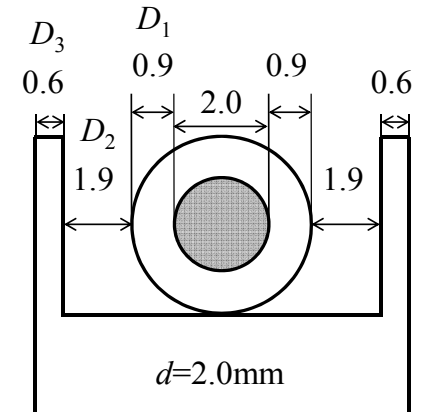

$D=2+1.8+3.8+1.2=8.8 \mathrm{~mm}$

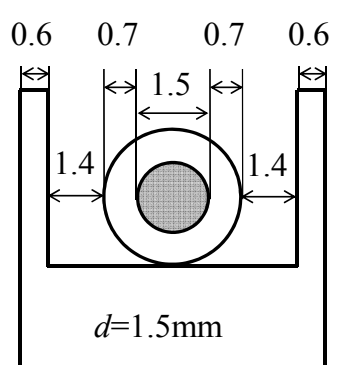

$D=1.5+1.4+2.8+1.2=6.9 \mathrm{~mm}$

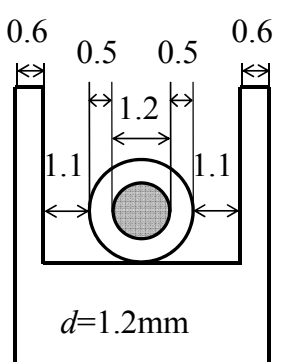

$D=1.2+1+2.2+1.2=5.6 \mathrm{~mm}$

$d$ : Diameter of SMA belt, $D_{1}$ : Thickness of sleeve, $D_{2}$ : Clearance, $D_{3}$ : Thickness of flange

Fig. 6 Depth of the SMA engine

\section{$7 \cdot 4$ SMA エンジンの出力密度 $P / V$}

最後にSMA エンジンの出力密度 $P / V$ について考える. SMA エンジンの体積は $V=W \times H \times D$ で求めることができる. また, SMA エンジンの出力 $P$ は導出した理論出力式を用いて求めることができる. したがって, 各 SMA ベルトの直 径における SMA エンジンの出力密度 $P / V$ は表 3 および図 7 に示すとおりとなる.

従来の研究成果(4)(5) より, SMA エンジンの出力 $P$ は SMA ベルトの直径 $d$ に強く依存し, SMA ベルトの直径 $d$ が大 きくなるほど出力は大きくなる.

一方，表 3 の成果を図 7 に示寸と，出力と同様の単調増加（実線）と考えることもできるが，むしろ SMA エンジン の出力密度が最大となる SMA ベルトの直径 $d$ が存在する（破線）可能性もあることが分かった.

Table 3 Appropriate values of the SMA engine

\begin{tabular}{|c|c|c|c|}
\hline Diameter of SMA belt $d[\mathrm{~mm}]$ & $1.2 \mathrm{~mm}$ & $1.5 \mathrm{~mm}$ & $2.0 \mathrm{~mm}$ \\
\hline Radius of high temperature wheel $r[\mathrm{~cm}]$ & $4.5 \mathrm{~cm}$ & $5.6 \mathrm{~cm}$ & $7.5 \mathrm{~cm}$ \\
\hline Radius of low temperature wheel $R[\mathrm{~cm}]$ & $12.5 \mathrm{~cm}$ & $12.5 \mathrm{~cm}$ & $20 \mathrm{~cm}$ \\
\hline Length of SMA belt $L[\mathrm{~m}]$ & $4.2 \mathrm{~m}$ & $5.2 \mathrm{~m}$ & $5.75 \mathrm{~m}$ \\
\hline Distance between centers of wheel $\ell[\mathrm{m}]$ & $1.83 \mathrm{~m}$ & $2.32 \mathrm{~m}$ & $2.44 \mathrm{~m}$ \\
\hline Width $W[\mathrm{~m}]$ & $0.25 \mathrm{~m}$ & $0.25 \mathrm{~m}$ & $0.4 \mathrm{~m}$ \\
\hline Height $H[\mathrm{~m}]$ & $2.00 \mathrm{~m}$ & $2.50 \mathrm{~m}$ & $2.72 \mathrm{~m}$ \\
\hline Depth $D[\mathrm{~m}]$ & $1.2 \times 10^{-3} \mathrm{~m}$ & $1.5 \times 10^{-3} \mathrm{~m}$ & $2.0 \times 10^{-3} \mathrm{~m}$ \\
\hline Volume of SMA engine $V\left[\mathrm{~m}^{3}\right]$ & $0.6 \times 10^{-3} \mathrm{~m}^{3}$ & $0.94 \times 10^{-3} \mathrm{~m}^{3}$ & $2.18 \times 10^{-3} \mathrm{~m}^{3}$ \\
\hline Theoretical value of output power $P[\mathrm{~W}]$ & $4.52 \mathrm{~W}$ & $8.36 \mathrm{~W}$ & $18.67 \mathrm{~W}$ \\
\hline Output power Density of SMA engine $P / V\left[\mathrm{~kW} / \mathrm{m}^{3}\right]$ & $7.5 \mathrm{~kW} / \mathrm{m}^{3}$ & $8.9 \mathrm{~kW} / \mathrm{m}^{3}$ & $8.6 \mathrm{~kW} / \mathrm{m}^{3}$ \\
\hline
\end{tabular}




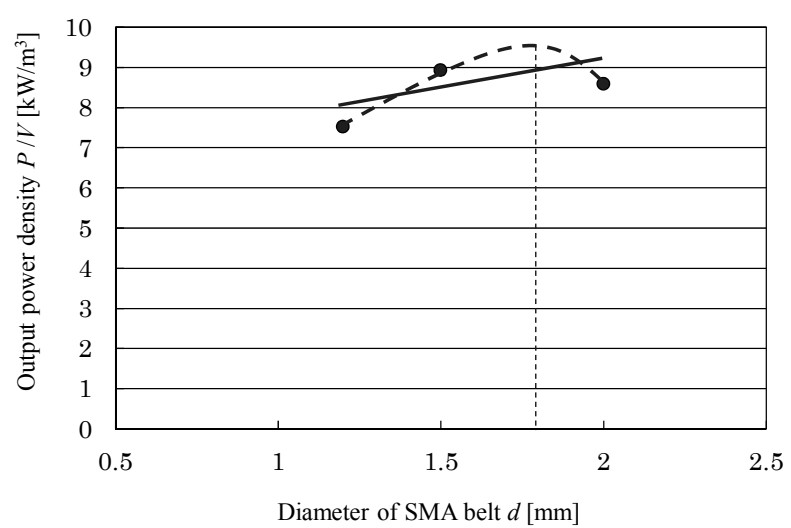

Fig. 7 Optimal power density

(When output power density of SMA engine reaches its maximum)

\section{8. まとめ}

本研究で得られた主な成果を以下にまとめて示寸.

(1)低温輪の半径 $R$ は，SMA ベルトの直径 $d$ を決めれば，導出した理論出力式を用いた解析より決定できる.

(2)SMA エンジンの装置の幅 $W$ は, 低温輪の半径 $R$ で決定することができる $(W=2 R)$.

(3)SMA エンジンの出力は, SMA ベルトの直径が大きいほど高くなるが, 出力密度に関しては, 出力密度が最大となる

SMA ベルトの直径が存在する可能性もあることがわかった.

以上のとおり，SMA エンジンの出力密度が最大となる設計手法に関する知見・ノウハウを得ることができ，SMA エ ンジンを用いた新発電システムの実用化に貢献することができた.

\section{文献}

(1) W.S.Ginell, J.L.McNichols Jr., and J.S.Cory, "Nitinol Heat Engines for low-grade thermal energy conversion”, Mechanical Engineering, Vol. 101, No. 5, (1979), pp.26-33.

(2) H.Tobushi, J.R.Cahoon, "Mechanical Analysis of a Solar-Powered Solid State Engine", Transactions of the Canadian Society of Mechanical Engineers, Vol. 9, No. 3, (1985), pp.137-141.

(3) 岩永弘之, 戸伏壽昭, 伊藤広道, “形状記憶合金熱エンジンの出力特性の基礎研究(第 1 報”, 日本機械学会論文集 A 編, Vol. 54, No. 497 (1987), pp. 177-180.

(4) 佐藤義久, 森本浩紀，吉嶺和哉，松川達也，“形状記憶合金エンジンの出力特性に関する研究(第 4 報)”, 日本機械学会論 文集 B 編, Vol. 76, No. 771 (2010), pp. 213-220.

(5) 佐藤義久, 吉嶺和哉, 森本浩紀, 藤田秀紀, “形状記憶合金エンジンの高出力化に関する研究”, 日本機械学会論文集 B 編, Vol. 76, No. 767 (2010), pp. 72-79. 